\title{
Nietzsche e o projeto crítico de superação da compreensibilidade
}

\author{
Jorge Luiz Viesenteiner*
}

\begin{abstract}
Resumo: O objetivo do texto é analisar o que denominamos projeto crítico de superação da compreensibilidade, a partir de três hipóteses: a) a temporalização do pensamento, remontando-o às condições individuais do emprego de um conceito, um signo, uma ação, etc.; b) essa individualidade do pensamento implica em compreendê-lo de modo fluido, de modo que tão logo se alterem as condições individuais do emprego de um conceito, altera-se também seu sentido; c) Nietzsche não parte mais da vontade incondicional de ser compreendido e, sobretudo, universal e univocamente compreendido, mas sim da hipótese de que "não se quer apenas ser compreendido quando se escreve, mas sim e de certa forma também não ser compreendido".

Palavras-chave: compreensibilidade - individualização - fluidez de sentido - incompreensibilidade
\end{abstract}

\section{O problema da compreensibilidade}

A primeira hipótese da superação do problema da compreensibilidade se refere ao questionamento que Nietzsche faz, segundo o qual qualquer um poderia compreender bem a um outro se assim o quisesse e se este outro se fizesse suficientemente claro. $\mathrm{O}$ discurso filosófico se caracteriza precisamente por essa pretensão de meta-compreensibilidade ou ainda de uma compreensão supra-individual, na medida em que uma doutrina ou sistema pressupõe

* Professor da Pontifícia Universidade Católica do Paraná (PUCPR), Curitiba, Paraná, Brasil. Email: jvies@uol.com.br. 
que alguém pode perfeitamente ser compreendido universalmente. ${ }^{1}$ Essa vontade de doutrina ou "vontade de sistema"2 que se arroga a compreensão supra-individual/universal é, segundo Nietzsche, um mero preconceito moral cultivado por milênios e, inclusive, uma patologia, sintoma de "cansaço da vida": "ela [a vida - JLV] não vale nada. [...] O que isso prova? O que isso indica? - Em outras épocas se teria dito [...]: 'Em todo caso, aqui algo tem de ser verdadeiro! O consensus sapientium prova a verdade.' - Falaríamos assim ainda hoje? Nos é lícito isso? 'Em todo caso, aqui tem de haver algo de doença" "(GD/CI, O problema de Sócrates 1, KSA 6.67). Ora, o consenso dos sábios não prova que a vida é uma doença e que "não vale nada", mas que esse consenso mostra uma patologia na sabedoria, qual seja, que se todos se compreendem mutuamente, então é verdade. Querer uma doutrina, por exemplo uma doutrina sobre a vida, é querer ser compreendido universal e univocamente por todos. Nesse sentido, a metafísica está, historicamente, ainda inserida no tempo das doutrinas e sistemas, na medida em que ela é "anseio por uma des-individualização da argumentação" e "exigência por uma doutrina supra-individual." "3 Trata-se da ideia de que os conceitos são independentes dos indivíduos, que esses conceitos podem ser também comunicados independentemente deles

1 Assim procedeu Kant em "Von einem neuerdings erhobenen vornehmen Ton in der Philosophie", A 417, 418. In: Werkausgabe in zwölf Bänden. Bd.6. Hrsg. von Wilhelm Weischedel. Frankfurt am Main: Suhrkamp, 1996: “A voz da razão (dictamen rationis) fala claramente para todo homem e é capaz de um conhecimento científico. Devemos, porém, ser capazes de entrever a priori, qual princípio poderia ou tornaria os homens melhores, caso o fosse trazido de forma clara e contínua às suas almas e fosse dada atenção à forte impressão que ele causa." Todas as traduções são de minha própria autoria.

2 Cf. GD/CI, Sentenças e flechas 26, KSA 6.63: "Desconfio de todos os sistemáticos e me retiro do seu caminho. A vontade de sistema é uma falta de probidade." Sobre a vontade de sistema confira ainda Nachlass/FP 1887, $9[181$ e 188], KSA 12.445/450; Nachlass/FP Novembro 1887/ Março 1888, 11[410], KSA 13.189; e Nachlass/FP Primavera 1888, 15[118], KSA 13.477.

3 Cf. STEGMAIER, W., Philosophieren als Vermeiden einer Lehre: Inter-individuelle Orientierung bei Sokrates und Platon, Nietzsche und Derrida. In: SIMON, J (org.), Distanz im Verstehen: Zeichen und Interpretation II. Frankfurt am Mai, 1995. p. 232. 
juntamente com seus significados e, por fim, que os indivíduos que comunicam não são influenciados por tais conceitos ou "que a comunicação em nada altera do que é comunicado." ${ }^{4}$

Toda "vontade de sistema" expressa através de uma doutrina é, pois, a exigência incondicional por uma compreensão inequívoca e de validade universal. Acrescente-se ainda que a instrumentalização desse imenso processo de des-individualização de argumentos é a criação de um sistema de conceitos e uma lógica que seja capaz de proceder às suas derivações, cujo fundamento é o "pendor predominante de considerar o semelhante como como igual", bem como a negação da "fluidez" mesma da vida (FW/GC 111, KSA 3.471). À base dessa exigência por compreensão universal está a des-individualização do próprio homem e das suas condições peculiares de vida, quer dizer, a exigência por ter algo "em comum" (gemein) com as coisas e com os outros. Gemein é uma palavra que também pode significar "vulgar" e "inferior". Neste aspecto, a exigência de compreensão universal é a des-individualização da própria vida em proveito de um gigantesco processo de vulgarização, na medida em que os indivíduos se comun-icam sempre sob determinadas condições de vida em que possuem algo 'em comum' entre si e com o mundo.

Assim, na metafísica, lógica, conhecimento, linguagem, moral, etc., há sempre uma doutrina que exige compreensão de validade universal e, portanto, ausência daquele pathos da distância, a distância característica da "alma superior e seletiva", a alma "nobre", que ao contrário da vulgar, anseia por não "querer ter nada em comum" (Nachlass/FP Maio/julho 1885, 35[76], KSA 11. 544s./f.). Com a superação da compreensibilidade, Nietzsche inaugura uma forma totalmente nova de filosofia - sobretudo a partir de 1880 -, na medida em que vai se aproximando gradativamente de uma filosofia da interpretação e dos signos que pressupõe, de antemão,

4 STEGMAIER, W., op. cit., p. 216. 
o distanciamento da situação na própria situação. É essa inversão de perspectiva que, segundo Nietzsche, exprime o que há de "novo" "à filosofia"5 e, sobretudo, é nesse aspecto que, como ele escreve, "nossa nova linguagem talvez soe de modo mais estranho" (JGB/BM 4, KSA 5.18). Ora, isso não significa outra coisa a não ser querer resgatar novamente a individualidade do seu pensamento: "Eu nunca me livrei, mesmo na mais curta proximidade, de um sentimento de distância que, em último caso, quisera ser fisiológico: eu sinto a distância para ser diferente em cada entendimento, igualmente inconfundível, e para estar acima em comparação com cada elemento opaco." (Nachlass/FP setembro/outubro 1888, 22[29], KSA 13.597) A nova forma inaugurada por Nietzsche de uma filosofia da interpretação e do signo, que implica precisamente na superação da compreensibilidade, é uma "filosofia da individualidade" .

A empresa crítica de superação da compreensibilidade em uma filosofia do uso individual dos signos enquanto signo começa a partir de 1880. Um apontamento do outono desse ano é revelador nesse aspecto:

Tão logo queiramos determinar a finalidade do homem, antecipamos um conceito de homem. Mas dos indivíduos conhecidos de até então, tal conceito só pode ser conquistado de tal modo que se retira toda individualidade - logo, estabelecer a finalidade do homem significaria coibir os indivíduos em sua individualidade ${ }^{[1]}$, ou seja, torná-los universais/ vulgares (allgemein $)^{[2]}$. Cada indivíduo, ao contrário, não deveria ser a tentativa de alcançar uma espécie mais elevada do que a do homem, de tal modo que possa ser sua coisa mais individual? ${ }^{[3]}$ Minha moral seria

5 Nachlass/FP Primavera 1880, 3[19], KSA 9.52: “A novidade em nossa última posição para com a filosofia é uma tradução que ainda não teve espaço em nenhuma época: que não tínhasmos a verdade." Cf. também Stegmaier, W. Nietzsches Neubestimmung der Wahrheit. In: Nietzsche-Studien 14 (1985) p. 69-95.

6 Cf. STEGMAIER, W., Philosophie als Vermeiden einer Lehre, p. 215. 
aquela de acolher o caráter universal do homem e especializá-lo até o ponto de se tornar incompreensível ${ }^{[4]}$ aos outros (e, com isso, objeto de vivências, admiração e ensinamento para eles) (Nachlass/FP Outono 1880, 6[158], KSA 9.237).

[1] O sequestro da individualidade ocorre na medida em que se estabelece, antecipadamente, um conceito universal de homem. Se compreendermos o homem como pathos, então ele passa a significar um conceito que não pode ser sistematicamente conceitualizado, mas antes, compreendido na sua mais rigorosa fluidez de sentido, cujo conceito se altera na medida em que as condições individuais do uso do signo 'homem' também se alteram, permanecendo, com isso, sempre fluido e aberto. ${ }^{7} \mathrm{~A}$ vontade de sistema é a des-individualização desse argumento: trata-se do estabelecimento de um conceito com validade [2] universal, cujo pressuposto é que ele pode ser compreendido univocamente por todos e, ao mesmo tempo, a definição do que há 'em comum' entre os homens, tornando-os vulgares. Logo em seguida, porém, Nietzsche questiona precisamente a compreensão universal, enfatizando que a reconquista da individualidade é a fórmula moral que aponta à superação do homem em direção a uma "espécie mais elevada". Eis aí uma fórmula moral empregada em um sentido extra-moral, pois a superação do homem ocorre na medida em que se questiona a compreensibilidade conceitual da ideia 'vulgar' de homem, em proveito de uma filosofia do uso individual dos signos. A fórmula moral de superação do homem implica, porém, a imoralidade do emprego dos signos que até então foram utilizados para 'conceitualizar' o homem. (Nachlass/FP Outono 1887, 10[57], KSA 12.485s./f.) Tão logo se consiga "de-moralizar o mundo"s (entmoralisiren) e operar

7 Cf. TONGEREN, Paul v. Die Moral von Nietzsches Moralkritik. Bonn: Bouvier Verlag, 1989. p. 76-79.

8 Nachlass/FP Inverno 1883/1884, 24[7], KSA 10.646: "Nosso anseio agora é o de de-moralizar o mundo: do contrário não se poderia mais viver." 
com a superação da compreensibilidade a fim de individualizar os conceitos, no sentido de retirar o emprego moralizado dos signos - por exemplo na compreensão universal do conceito homem -, então, [3] o homem se tornaria "a coisa mais individual". Apesar de empregar a fórmula moral da superação, Nietzsche opera em um sentido extra-moral, na medida em que, ao individualizar e "especializar" o conceito de homem retirando seu "caráter universal", ele se tornaria [4] "incompreensível", pois não mais universal e nem vulgar. $\mathrm{Na}$ superação da compreensibilidade, a radical individualidade de um pensamento, do homem, da vida, enfim, retira precisamente o que há 'em comum' uns com os outros; retira toda concordância e, portanto, toda moralidade da linguagem conceitual. A fórmula moral de Nietzsche é, pois, totalmente extra-moral. Assim ele consegue se distanciar tradição filosófica, empregando os meios dessa mesma tradição e, portanto, distancia-se da situação na própria situação.

A superação da compreensibilidade opera também com o emprego de paradoxos. É provável que nenhum outro filósofo tenha sido tão estilisticamente paradoxal quanto Nietzsche. O paradoxo, porém, é uma estratégia literária empregada para se distanciar precisamente da des-individualização da argumentação, des-estabilizar os conceitos e ampliar as margens de manobra de interpretação: "Através do auto-emprego de diferenciações (como verdadeiro e falso, bem e mal, forte e fraco), Nietzsche intencionalmente produziu paradoxos a fim de desconcertar as diferenciações filosóficas fixadas e, com isso, conquistar novas margens de manobra (Spielräume) para o pensamento."9 Nesse caso, como estratégia literária, o paradoxo se relaciona também indiretamente com a

9 STEGMAIER, W. „Philosophischer Idealismus“ und die „Musik des Lebens“: zu Nietzsches Umgang mit Paradoxien. In: Nietzsche-Studien 33 (2004), p. 90-128, aqui p. 93. O grifo é nosso. Cf. também sobre o tema DIXSAUT, Monique. Nietzsche: Par-delà les antinomies. Chatou: Les Éditions de la Transparence, 2006; ALMEIDA, Rogério Miranda. Nietzsche e o paradoxo. São Paulo: Loyola, 2005. 
individualização do pensamento, tão logo paradoxaliza aquilo que pretensamente arroga a universalidade. Não apenas amplia margens de interpretação, como também, ao ampliá-las, distancia-se das pretensões unívocas e universalizantes do discurso, relegando ao indivíduo as possibilidades de interpretação. Assim, na medida em que Nietzsche des-estabiliza um conceito e inverte a compreensibilidade através do paradoxo, ele cria, portanto, novas Spielräume de interpretação. Isso significa que o horizonte e o sentido de algo podem ser continuamente deslocados e reinterpretados, assim que as "margens de manobra" do conceito sejam ampliadas. ${ }^{10}$ Nietzsche emprega a palavra Spielraum tanto em seu sentido geral ${ }^{11}$ quanto no âmbito de uma filosofia da interpretação e dos signos. Tal é o caso do aforismo 27 de Para além de bem e mal.

10 Segundo o verbete „Spielraum“, In: KNEBEL, Sven K. Historisches Wörterbuch der Philosophie. Bd. 9. Basel/Stuttgart: Schwabe \& Co. Verlag, 1972. p. 1390-1392, o termo Spielraum foi empregado originalmente às designações da "mecânica", especialmente de uso militar, em relação à "diferença entre o calibre do canhão e o diâmetro do projétil". Para que o projétil pudesse atingir corretamente seu destino, o Spielraum entre eles deveria estar corretamente dimensionado. O uso geral do termo, porém, ocorre apenas no século XVIII e passa a designar "mais ou menos o espaço de atuação delimitado da ação de possibilidades" $(H W P h$., p. 1390). Desde o "Círculo de Viena", especialmente Wittgenstein, o termo Spielraum se torna um "conceito fundamental" no âmbito da filosofia da linguagem e da lógica formal, pois "ele se refere à totalidade das proposições elementares permitidas e é definido através de casos limites, tautologia e contradição" (HWPh., p. 1391). No Aforismo 194 das Investigações filosóficas, Wittgenstein também empregou o termo no sentido geral que Spielraum recebe a partir do século XVIII, a propósito da pergunta: "Teria a máquina, de uma forma misteriosa, seus possíveis movimentos já em si? [...] $\mathrm{O}$ que são as condições de movimento? Elas não são o movimento; mas também não parecem ser a mera condição física do movimento - o Spielraum que há entre o pino e o mancal, de modo que o pino não se adapte tão estreitamente ao mancal". WITTGENSTEIN, L. Philosophische Untersuchungen. Frankfurt am Main: Suhrkamp Verlag, 2003. Cf. também AZEREDO, Vânia D. Nietzsche e a interpretação: do mundo ao texto. In: BARRENECHEA, Miguel; FEITOSA, Charles; Pinheiro, PAULO; Suarez, Rosana. (Org.). Nietzsche e as ciências. 1 ed. Rio de Janeiro: 7 Letras, 2011, v. 1, p. 202-213.

11 Cf., p.ex., Nachlass/FP Primavera/verão 1888, 16[7], KSA 13.485: “O domínio sobre as paixões e não seu enfraquecimento ou extirpação! Quanto maior é a força de domínio de nossa vontade, tanto mais liberdade pode ser dada às paixões. $\mathrm{O}$ grande homem é grande através da margem de manobra de liberdade de seus apetites (Freiheits-Spielraum): mas ele é forte o suficiente para, desses selvagens apetites, domesticá-los." Em um apontamento de novembro 1887/março de 1888, 11[400], Nietzsche registra ainda que a "originalidade de alguém" pressupõe também uma "livre margem de manobra". 
Ali Nietzsche inicia o texto escrevendo que a compreensão não é tão evidente como as filosofias de sistemas dão a entender, pois, tal como escreve, "é difícil ser compreendido". Não há Spielraum em doutrinas e, portanto, nenhuma "sutileza de interpretação". No aforismo Nietzsche escreve três palavras em sânscrito ao se referir à dificuldade de viver entre homens que "pensam e vivem de outra maneira, ou seja, kurmagati ou, no melhor caso, "conforme o caminhar da rã", mandeikagati", quando ele próprio "pensa e vive gangsrotogati". Correspondendo aos ritmos musicais "lento", "staccato" e "presto" (Nachlass/FP 1886, 3[18], KSA 12.175), respectivamente, Nietzsche parece confrontar as Spielräume de perspectivas com as quais se avalia algo: a "kurmagati", o ritmo da tartaruga, lento, pesado e com o ângulo de perspectiva estreitamente colado no chão; a "mandeikagati" - "conforme o caminhar da rã" -, que se refere propriamente à expressão alemã "perspectiva da rã" que, na linguagem nietzscheana, é uma perspectiva ingênua e de única direção, vale dizer, de baixo para cima. ${ }^{12}$ Essa é a perspectiva dos mestres de doutrinas, os metafísicos, com suas "estimativas de fachada" e igualmente de apenas "um ângulo": uma "perspectiva de rã" (JGB/BM 2, KSA 5.16) ${ }^{13}$ de tal modo limitada que não permite um amplo espaço de atuação, mas ao contrário, apenas uma única avaliação de validade unívoco-universal.

À perspectiva de rã, de baixo para cima, Nietzsche confronta uma outra: "de cima para baixo"14, na medida em que desse ângulo é possível abarcar muito mais detalhes com a visão, ou seja,

12 No alemão, a expressão „Frosch-Perspektive“ significa precisamente um determinado ângulo que o pintor utiliza, neste caso, tal como a perspectiva da rã, ou seja, "de baixo para cima".

13 Em um apontamento póstumo de agosto/setembro de 1885, 40[44], KSA 11.651s./f., além dos metafísicos, Nietzsche também se refere à "perspectiva de rã" para designar a inocência nas avaliações morais: "Que se prejudique na medida em que não se diz a verdade é a crença dos inocentes: uma forma de perspectiva de rã da moral".

14 Cf. Nachlass/FP Outono 1886/1886, 2[182], KSA 12.157: "Entende-se que a perspectiva de baixo para cima dará expressões totalmente diferentes, do que aquela de cima para baixo." Ainda sobre o privilégio da perspectiva de cima para baixo, cf. Nachlass/FP Final de 1886/ Primavera 1887, 7[70], KSA 12.321s./f. 
ganha-se muito mais Spielraum. Essa é a perspectiva que se tem entre "bons amigos", entre seletos amigos que, "de antemão", não precisam da universalidade na compreensão. Entre "bons amigos", ao contrário, "concede-se" uma ampla "margem de manobra (Spielraum) e arena (Tummenplatz) para mal-entendidos" (JGB/BM 27, KSA 5.46) ${ }^{15} \mathrm{Na}$ amizade, há muito mais sutilezas de interpretação, nuances e mais fluidez nos significados, pois no horizonte de um determinado conceito, concede-se, entre "bons amigos", ampla Spielraum para "mal-entendidos", ou seja, seu sentido se desloca de modo muito mais livre. Conceder Spielraum para "mal-entendidos" é uma prerrogativa daqueles que abandonaram as doutrinas e sistemas para comunicar uma perspectiva. Ora, quando se tem sutileza na interpretação, como é o caso entre "bons amigos", um pensamento é propriamente tomado simplesmente como "signo" e, enquanto tal, fluido ${ }^{16}$.

2. O conceito de fluidez e seu papel de deslocamento de sentido

No âmbito de uma filosofia da interpretação e dos signos, o termo Spielraum implica necessariamente em fluidez de significado. Ao criar um paradoxo para ganhar mais margem de manobra de sentidos, Nietzsche se refere à fluidez que um mesmo conceito possui, sempre que se alteram as condições em que ele é empregado. Assim é que o uso de ambiguidades e paradoxos é também um meio

15 Originalmente, Nietzsche havia pensado esse aforismo para ser escrito em primeira pessoa. No esboço ao texto, in: KSA 14.351, Nietzsche registra que, inclusive, é difícil entendê-lo: "É difícil me entender; e eu seria um tolo se não desse aos meus amigos uma margem de manobra para mal-entendido, e se não < fosse $>$, de boa vontade, agradecido à alguma liberdade de interpretação."

16 Cf. JGB/BM 283, KSA 5.231: "Para ser lícito possuir esse efetivo luxo de gosto e moralidade, tem-se de viver não entre grosseirões do espírito, mas muito mais entre homens nos quais os mal-entendidos e equívocos divergem ainda através da sua sutileza." Sobre o tema, cf. também STEGAMAIER, W. Nietzsches Zeichen. In: Nietzsche-Studien 29 (2000), p. 41-69. 
com o qual Nietzsche leva a termo a superação da compreensibilidade. Quanto maior a margem de manobra para "mal-entendidos", maior é a fluidez de sentido ${ }^{17}$, e a fluidez é a segunda hipótese, a nosso ver, do projeto de superação da compreensibilidade.

O pensamento da fluidez significa substância no fluxo, e "responde, por um lado, ao pensamento metafísico da substância, o pensamento de uma unidade incondicional e independente em todas as mudanças [...]. Por outro lado, ele responde ao pensamento de desenvolvimento científico, na medida em que, a partir de um conceito crítico de vida, pensa essa 'unidade independente' no fluxo de suas condições de vida, o fluxo através do qual sua independência é novamente contestada e, ao mesmo tempo, que possibilita uma contestação sempre de uma maneira diferente". Trata-se, pois, de um pensamento que se refere a algo que nunca pode ser desvinculado da pressão do tempo, da história e suas sempre mutáveis condições de vida, de modo que o "pensamento da fluidez" passa a "expressar a mutabilidade da essência de uma unidade de vida em sua rede vital e, com isso, a liberdade da vida e da história". Assim, tão logo se alterem as condições de vida ou mesmo as condições de emprego de um conceito, seu sentido também será continuamente deslocado.

17 Essa é a relação que está presente no atual debate da filosofia da orientação. Cf. STEGMAIER, W. Philosophie der Orientierung. Berlin/New York: Walter de Gruyter, 2008. p. 221. Do ponto de vista moral, toda ação também será necessariamente fluida, na medida em que, em um determinado espaço com regras mais ou menos delimitadas, a mesma ação pode se ampliar e tomar outros significados sempre que os participantes da comunicação também assim concederem. A fluidez da ação no interior do Spielraum é um "limite regulado de comportamentos não-regulados": "Uma margem de manobra é um espaço e, porém, nenhum espaço, e nele há um jogo e, porém, nenhum jogo; em todo caso, há um uso corrente de 'margem de manobra' na 'margem de manobra da ação'; na ligação entre 'espaço' e 'jogo' se desloca o sentido de ambos. Não se esperando de outra forma, a metáfora da margem de manobra acolhe e oculta um paradoxo. Uma margem de manobra é o 'espaço' de um movimento limitado por regras, no qual é possível um rápido 'movimento' que não obedeça a essas regras, no interior do qual, neste sentido, é possível um 'jogo' livre dessas regras. Em resumo: um limite regulado de comportamentos não-regulados. 'No interior' desse limite o comportamento pode provavelmente obedecer a regras próprias." 
Portanto, sob a pressão do tempo, o sentido se desloca sem que se possa fixar um conceito de uma vez por todas, tomando-o apenas como mero signo sempre fluido. ${ }^{18}$

Uma palavra para fluidez é nuance, especialmente a fórmula que Nietzsche utiliza para si mesmo: "eu sou uma nuance!" (EH/ EH, O caso Wagner 4, KSA 6.362) ${ }^{19}$. Uma 'nuance' é um distanciamento em relação ao conceito, ou melhor, é a diferença em relação ao conceito. Se o conceito exige uma adequada compreensão, e esta sempre de modo universal e unívoca, a nuance, ao contrário, não se deixa compreender tal como compreendemos um conceito, isto é, unívoca e universalmente; uma nuance não pode ser conceitualizada, pois ela se distancia e se desvia do próprio conceito. Tão logo conceitualizamos a nuance, ela o deixa de ser e se torna uso ‘em comum' de signos de comunicação, torna-se conceito e não nuance, torna-se universal e unívoca, e não sutil. Quando se pensa compreender bem uma nuance, ou quando pensamos que compreendemos bem a Nietzsche, revela-se logo um mal-entendido, pois se trata de um estilo que se desvia ou foge à conceitualização. ${ }^{20}$ Não é possível conceitualizar alguém ou um estilo que é propriamente uma 'nuance': aí se faz necessário unicamente "sutileza de interpretação", pois a nuance é uma "margem de manobra para mal-entendido" (Nachlass/FP Outono 1885/Primavera 1886, 1[182], KSA 12.50s./f.).

18 STEGMAIER, W., Philosophie der Fluktuanz: Dilthey und Nietzsche. Göttingen: Vandenhoeck \& Ruprecht, 1992. p. 190s./f.

19 Sobre a análise dessa fórmula, cf. WOTLING, P. Nietzsche et le problème de la civilasation. Paris: PUF, 1995, especialmente o capítulo em que o autor analisa a fórmula "eu sou uma nuance".

20 STEGMAIER, W. Nietzsches Kritik der Vernunft seines Lebens: Zur Deutung von „Der Antichrist“ und „Ecce Homo“. In: Nietzsche-Studien 21 (1992), p. 163-183, aqui na p. 170s./f.: "Uma nuance é um desvio; pode-se compreendê-la apenas através de um conceito do qual ela se desvia e, porém, só a teremos compreendido se não a compreendermos tal como um conceito, do qual a nuance se desvia. Portanto, ter-se-á mal-compreendido essa nuance precisamente se se acredita tê-la 'bem' compreendido, ou seja, conforme conceitos comuns e também já compreensíveis." 
Quando Nietzsche diz de si mesmo que é uma nuance, significa que ele quer ser compreendido, porém, simultaneamente, que ele também quer 'não ser compreendido': ele cria um paradoxo em relação a si mesmo e, assim, cria um pathos ou "sentimento de distância" em relação à compreensão. Ao comunicar, Nietzsche imediatamente se distancia do significado mesmo daquilo que é comunicado, passando assim a significar algo diferente daquilo que originalmente significava, empregando então semioticamente um termo, a fim de comunicar seu próprio pensamento. Por isso, sendo uma nuance, ele se desvia da possibilidade de sistematizar conceitualmente aquilo que ele comunica, resultando em um mal-entendido em relação àquele que tenta sistematizá-lo sob a égide de uma doutrina. Ao criar uma ampla Spielraum para mal-entendidos, bem como conferir extrema fluidez a sua escrita, Nietzsche retira toda univocidade de comunicação e, sobretudo, toda possibilidade de representação conceitual através do uso de signos "em comum".

Sendo uma nuance, não se deve mais perguntar pelo significado de algo, pois tão logo se pergunte pelo significado, cria-se logo um mal-entendido em relação ao significado daquilo que se perguntou. Resta, portanto, no interior da condição paradoxal de ser uma nuance, compreendê-lo não mais em seu significado - que sempre se desvia - mas apenas como signo.

Em Para a Genealogia da Moral Nietzsche registrou em que medida um conceito, uma regra, uma ação, enfim a "história de uma "coisa"" "é sempre reinterpretado", enquanto signo, "em vistas de novas coisas, retomado de uma maneira nova, repensado e redirecionado para uma nova utilidade." (GM/GM II, 12, KSA 5.314) O uso do paradoxo e a ideia de nuance torna fluido todo sentido, desde que se considere, como Nietzsche o fez, que também "o pensamento é, da mesma forma que a palavra, apenas um signo, de que não pode estar em questão qualquer correspondência do pensamento com o real" (Nachlass/FP Outono 1880, 6[253], KSA 9.263. O grifo é nosso). Sob o signo da fluidez, o sentido de um conceito tem sua Spielraum ampliada, de modo que ele pode continuamente se 
modificar e deslocar, sempre que estiver sendo empregado sob outras condições individuais de vida e, além disso, que seja também compreendido apenas como "um signo". Dessa forma, algo pode ser "uma contínua cadeia de signos de sempre novas interpretações e reorganizações, cujas causas não precisam estar em um mesmo contexto entre si, mas muito mais que se seguem e se sucedem umas às outras sob circunstâncias meramente fortuitas." (GM/GM II, 12, KSA 5.314 ${ }^{21}$ É sob os registros de Spielraum e fluidez de sentido, pois, que se compreende melhor a fórmula de Nietzsche que reza: "Não há quaisquer fenômenos morais, mas apenas uma interpretação moral dos fenômenos." (JGB/BM 108, KSA 5.92)22 Quando se inverte a compreensibilidade e se assume a perspectiva que tudo é "apenas signo" possível estabelecer a forma conceitual fixa, na medida em que só é "definível... aquilo que não tem história" (GM/GM II, 13, KSA 5.317), convertendo-se, portanto, em fluidez. Em suma: “A forma é fluida, o "sentido' o é ainda mais..." (GM/GM II, 12, KSA 5.315).

Ao questionar a univocidade da compreensão, Nietzsche remonta às condições fundamentais de comunicação, como comunicação entre indivíduos. A partir da superação da compreensibilidade, não é mais possível, portanto, compreender alguém ou um pensamento a partir de uma validade universal, mas apenas sob determinadas condições peculiares de vida e, sobretudo, individualmente.

21 Sobre esse tema e sua relação com a vontade de poder, cf. STEGMAIER, W. Nietzsches Genealogie der Moral. Darmstadt: Wissenschaftliche Buchgesellschaft, 1994. p. 70-88; SIMON, J. Der gewollte Schein: Zu Nietzsches Begriff der Interpretation. In: DJURI冈, M u. SIMON, J. Kunst und Wissenschaft bei Nietzsche. p. 62-74.

22 Cf. ainda GD/CI, Os melhoradores da humanidade 1, KSA 6.98; Nachlass/FP Outono 1885/Outono 1886, 2[165], KSA 12.147.

23 Cf. o apontamento pensado como continuação a Para além de bem e mal, Nachlass/FP Outono 1885/Outono 1886, 2[82], KSA 12.100: “Interpretação, e não explicação. Não há nenhum fato, tudo é fluido, não-sistematizável, sempre cedendo; [...] Inserir sentido - na maioria dos casos é uma nova interpretação que se sobrepôs a uma antiga interpretação tornada incompreensível que, agora, é apenas signo." 
Viesenteiner, J. L.

\section{A superação da tese hermenêutica da compreensibilidade.}

Nietzsche é um filósofo radicalmente consciente da tese hermenêutica, segundo a qual a compreensão só é possível como um mal-entendido. A análise da terceira e última hipótese da superação da compreensibilidade se refere ao aforismo 381 d'A Gaia Ciência, intitulado precisamente Sobre a questão da compreensibilidade (Zur Frage der Verständlichkeit). Ali, logo de início Nietzsche lança a premissa central da sua forma de escrita: "Não se quer apenas ser compreendido quando se escreve, mas sim e de certa forma também não ser compreendido." (FW/GC 381, KSA 3.633) ${ }^{24}$ Ou seja, ao escrever, não se deve querer ser compreendido da mesma maneira por todos e, além disso, não se deve querer, ofensivamente, que todos compreendam determinadas ações, na medida em que se assim o for, elas são de tal modo vivências 'em comum', que qualquer um pode compreendê-las. ${ }^{25}$ Apenas entre "amigos", como vimos, concede-se uma "ampla margem de manobra para mal-entendido", na medida em que, entre "bons amigos", a não-concordância não é ofensiva, mas revela uma tal "sutileza de interpretação", que eles inclusive podem se divertir com os equívocos.

24 No apontamento Nachlass/FP do outono de 1885, 44[6], KSA 11.707, Nietzsche se refere a algumas "formas de homem" que foram "mal compreendidos": "eles devem ser mal compreendidos", como é o caso de "Epicuro.”. Cf. ainda JGB/BM 25, 27, 40, 270, 290; GM/GM, Prefácio 1; EH/EH, Prólogo 1.

25 Cf. Nachlass/FP Outono 1885/Primavera 1886, 1[182], KSA 12.50: „,...] há algo de ofensivo em ser compreendido“. Ofende-se tanto por ser compreendido quanto por ser incompreendido. $\mathrm{O}$ primeiro caso é ofensivo àquele a quem viveu ou agiu e foi facilmente compreendido por todos, por conta da trivialidade e insignificância do vivido. No segundo caso, a incompreensão diante de algo pode ofender pela "frieza": "permanece-se frio em relação àquilo que não se compreende, e a frieza ofende". Por isso, como escreve Nietzsche, "agrada-se mais quando se é mal-entendido (mißverstanden) do que quando se é incompreendido (unverstanden)." Cf. também Nachlass/FP Primavera/Verão 1883, 7[155], KSA 10.293: "Nossas ações devem ser falsamente compreendidas, tal como Epicuro foi compreendido de maneira falsa! [...] Devemos ter somente homens cujo significado se torne manifesto após milênios — [...] Eu não quero ser compreendido por muito tempo." 
O aforismo 381 continua: "Não é uma objeção em absoluto a um livro, quando alguém o tome por incompreensível: talvez isso faça parte igualmente das intenções do autor - ele não queria ser compreendido 'por qualquer um'." Um mal-entendido sobre um texto ou pessoa é, definitivamente, sinal de distinção e nobreza. Significa que tal indivíduo não partilha do mesmo prato do seu tempo, ou que tem vivências superiores a seus contemporâneos. Alguns homens "póstumos", e Nietzsche se incluía $\mathrm{a}^{26}$ entre eles, são de difícil compreensão e, "em certo sentido nunca compreendidos" (Nachlass/FP Outono 1887, 9[76], KSA 12.375) ${ }^{27}$. Todo mal-entendido, neste aspecto, é expressão de um extremo distanciamento de uma dada situação e, portanto, um sinônimo de originalidade. Ao contrário do emprego de palavras semelhantes para comunicar vivências também recorrentes, Nietzsche deixa registrado que suas "vivências, avaliações e anseios internos são diferentes" (Nachlass/FP Abril/Junho 1885, 34[86], KSA 11.448). Distanciando-se, pois, do que há 'em comum', ele escreve através de signos que, apesar de serem os mesmos empregados no interior da Gemeinheit, são tomados, por um lado, apenas como signos e, por outro lado, signos que são mal-entendidos, visto expressarem vivências também diferenciadas.

Pensemos então em um caso extremo, em que um livro fale de vivências de tal modo interiores, que se situem totalmente fora da possibilidade de uma experiência corriqueira ou também rara, - que ele seja a primeira linguagem para uma série de experiências. Nesse caso, nada

26 EH/EH, Por escrevo tão bons livros 1, KSA 6.298: “Antes de começar a falar dos meus escritos, tocarei aqui na questão da compreensão ou não-compreensão desses escritos. Eu o faço de tal modo negligente, [...] pois essa não é ainda a época para essa pergunta. Eu mesmo não sou ainda para essa época, alguns homens nasceram póstumos." O grifo é nosso.

27 Nietzsche atribuiu a essa incompreensão, inclusive, a autoridade de um texto e uma pessoa: "Homens póstumos - eu, por exemplo - são compreendidos de uma maneira pior do que os contemporâneos, porém, muito melhor ouvidos. Dito mais rigorosamente: não seremos nunca compreendidos - e por isso nossa autoridade..." (GD/CI, Sentenças e flechas 15, KSA 6.61). 
se ouvirá, com a ilusão acústica de que ali onde nada é ouvido, também nada existe... Essa é, definitivamente, minha experiência ordinária e, se se quiser, a originalidade da minha experiência. Quem tenha acreditado compreender algo de mim, esse me refez à sua imagem - não raramente um oposto de mim, por exemplo um 'idealista'; quem não compreendeu nada de mim, negou que eu tivesse de ser levado em consideração (EH/EH, Por que escrevo tão bons livros 1, KSA 6.300 $)^{28}$.

Essa é a originalidade do seu pathos, a originalidade da sua escrita. No mesmo contexto do 381, o aforismo 371 também d'A Gaia Ciência, intitulado "Nós, os incompreensíveis", Nietzsche leva às últimas consequências a hipótese de não ser compreendido, ao situar a incompreensão como a virtude mesma pertencente à sua "sina": "Já nos queixamos alguma vez de ser mal-compreendido, mal conhecidos, confundidos, caluniados, mal ouvidos ou ignorados? Isso é propriamente nossa sina" (FW/GC 371, KSA 3.622) ${ }^{29}$. Nietzsche reconhece o limite da linguagem, o limite em comunicar uma vivência que expresse a abundância. Por isso se distancia dos signos 'em comum', sobretudo ao comunicar um pathos que está em muito nas "alturas" e distanciado. Na medida em que não formula mais tal "vida", ou não formula mais o pathos de um tal homem sob um sistema universal, seu destino só poderia ser a incompreensão, ou ainda, aquilo que ele nunca desejou compartilhar. Ao superar a compreensibilidade unívoca, bem como ao tomar distância da Gemeinheit, ou se opera no âmbito de uma filosofia da interpretação e dos signos, ou talvez, sob o signo de uma filosofia do silêncio: "Eis nossa sina, como se disse: crescemos às alturas; e posto que ainda fosse nossa fatalidade mesma $[\ldots]$, pois bem, não nos

28 Cf. também MA II/HH II, WS/AS 122, KSA 2.604: “O original é, usualmente, olhado com admiração, entre alguns até mesmo adorado, porém, é raramente compreendido; desviar-se obstinadamente às convenções, significa: não querer ser compreendido."

29 Cf. Nachlass/FP Outono 1885/Outono 1886, 2[79], KSA 12.99 e Nachlass/FP Setembro/ Outubro 1888, 22[28], KSA 13.596. 
reverenciaríamos menos por isso, isso permanece sendo o que não queremos partilhar, comunicar, a fatalidade das alturas, nossa fatalidade..." (FW/GC 371, KSA 3.623).

Se Nietzsche não partilha as mesmas vivências, também não quer, simultaneamente, ser "ouvido" por qualquer um. Assim ele também procede com sua nova Schriftstellerei, vale dizer, selecionando seus leitores:

Quando quer comunicar, todo espírito e gosto mais nobre escolhe também seus ouvintes; na medida em que ele os escolhe, estabelece simultaneamente seus limites em relação 'aos outros'. Todas as mais sutis leis de um estilo possuem aí sua origem: elas ficam ao longe, criam distância, proíbem 'a entrada', a compreensão, como se disse ao passo que abrem os ouvidos para aqueles que nos são aparentados pelos ouvidos (FW/GC 381, KSA 3.634).

Nietzsche expõe o leitor a um experimento de seleção e cultivo, "a fim de selecionar homens entre os quais se possa guardar e mostrar seu ideal de humanidade" (Nachlass/FP Primavera 1880/ Primavera 1881, 10[B38], KSA 9.421), cujos critérios basilares de seleção são a nobreza de 'espírito e gosto' e o ouvido!

Nobreza é sinal de distinção ${ }^{30}$, signo de alguém que também partilha as alturas; pertence àqueles homens que preferem não comunicar nem partilhar certas vivências, pertence àquele que conquistou a independência e, sobretudo, àquela alma que "tem reverência diante de si mesma" (JGB/BM 287, KSA 5.233). Nobreza é ser capaz de se distanciar da situação na própria situação, ou seja, afastar, criar distância é justamente estabelecer "limites em relação "aos outros" e impedi-los "a entrada". O próprio título do livro V d'A Gaia Ciência se chama "nós, os destemidos". Não se trata de

30 JGB/BM 271, KSA 5.226: "um tal pendor que distingue - é um nobre pendor - igualmente também é um pendor que separa". 
um livro para todos, mas àqueles que pertencem ao seleto grupo do "nós". Especialmente no livro V, Nietzsche se refere freqüentemente a esse "nós": "nós, os destemidos", "nós, artistas", "nossa interrogação", "nós, os incompreensíveis", "Porque não somos idealistas", "Nosso novo "infinito", "Nossos tempos lentos", "nós, os sem nome", "nós, os sem-pátria", etc. ${ }^{31}$ Como foi visto, apenas aos "bons amigos" é concedida Spielraum a mal-entendidos, pois apenas eles possuem a prerrogativa da "sutileza de interpretação". No 381, Nietzsche se dirige precisamente aos seus seletos leitores como "meus amigos". Pois se sua linguagem é incompreendida em meio à Gemeinheit, entre bons amigos é possível pelo menos rir diante de mal-entendidos.

Assim, ao mesmo tempo em que cria distâncias, quer abrir também "os ouvidos para aqueles que nos são aparentados pelos ouvidos". Em quase todas as referências em que Nietzsche levanta a hipótese de 'não ser compreendido', ele não se refere a dificuldades de leitura, ou a alguma diferença em relação ao texto, mesmo nos aforismos. Ao contrário, sua alusão não é quanto à sistematização, mas quanto ao ouvido. Ele não quer leitores que tenham vivências semelhantes às suas, mas ouvidos aparentados aos seus: "Mas seria uma completa contradição em relação a mim, se hoje esperasse já ouvidos e mãos para minhas verdades: que hoje não se ouça, que hoje não saibam receber nada de mim, não é apenas compreensível, mas me parece até mesmo justo" (EH/EH, Por que escrevo tão bons livros 1 , KSA 6.298) ${ }^{32}$.

Os aparentados pelo ouvido são os leitores que preferem "intuir", ao invés de "deduzir"; e que são atraídos "com flautas" e não com fórmulas. ${ }^{33}$ Selecionar os leitores pelos ouvidos significa pôr

31 Sobre essa questão, cf. CONWAY, D. Nietzsche's On the Genealogy of Morals: a Reader's Guide. London, UK / New York, USA: Continuum, 2008, p.ex., p. 20.

32 Cf. também EH/EH, Prólogo 1 e FW/GC 371.

33 EH/EH, Por que escrevo tão bons livros 3, KSA 6.303s.f. Nesse aforismo, Nietzsche cita o trecho "Da visão e do enigma", registrado no Zaratustra, quando se refere à "imagem de um leitor perfeito". 
em curso a caríssima hipótese, segundo a qual o texto nietzscheano deve ser lido tal como se ouvisse música. ${ }^{34}$ Trata-se então da ideia de que um tal texto não pode ser compreendido conceitualmente, ou seja, buscando por significados ou tentando "pôr em fórmulas" (FW/GC 373, KSA 3.626), mas apenas como signo: "Isso significa que seus leitores devem ao ler, ouvir, devem poder ler um texto como se ouve música: não apenas melodias e Leitmotive, mas também tons maiores e menores, tempo, ritmo, fraseados, etc.". 35 A seleção dos bons ouvintes significa, portanto, escolher aqueles que, por um lado, não exigem mais uma compreensibilidade unívoca e, por outro lado, que são capazes de ler um texto sem conceituá-lo sistematicamente, mas sim como música, linguagem esta que está aquém da sistematização conceitual. O texto 381 termina precisamente

34 Cf. o importante texto de Babich, Babette E. On Nietzsche's concinnity: an analysis of style. In: Nietzsche-Studien 19 (1990) p. 59-80 e em especial a nota 17, a propósito da ampla bibliografia que relaciona o estilo literário de Nietzsche e a música. A autora denomina o estilo literário de Nietzsche como "elegância literária" (concinnity), ou seja, uma "metáfora musical que sugere a ressonância entre as palavras de Nietzsche e a harmonização da leitura (dos leitores) com elas". (p. 59). A autora também parte da hipótese de que "Nietzsche repudiou a catolicidade (universalidade - JLV) da comunicação", de modo que o acesso a seus textos deveria se dar àqueles leitores "para quem o texto não é uma inscrição conceitual" (p. 61), ou seja, Nietzsche estava "consciente do problema hermenêutico", isto é, "que compreensão é sempre possível como um mal-entendido" (p. 61; 63). Neste aspecto, é preciso compreender que "antes de usar o texto para comunicar um significado para além do texto [...], o estilo de escrita de Nietzsche usa o texto para sugerir e interromper o conteúdo" (p. 73). Assim, o texto de Nietzsche nunca tem um valor de caráter universal, mas o significado último sempre se altera. Aí é que entra a habilidade de audição do leitor, na medida em que este precisa proceder a uma interpretação do texto de Nietzsche como música (p. 65). Um bom leitor precisa, antes de interpretação, ter um bom ouvido. Trata-se da necessidade de harmonizar a dificuldade de acessar o texto de Nietzsche, com suas múltiplas variações e equívocos, com a leitura que o próprio leitor faz dele. Por isso o termo musical que alude à harmonização. Do ponto de vista filosófico, a "elegância literária" de Nietzsche é, no fundo, uma auto-desconstrução do texto que o leitor precisa "ouvir": "O que eu denomino de elegância literária é uma desconstrução das expectativas do leitor em relação ao texto, pelo desafio do texto em si mesmo, tornando o texto inacessível ao leitor incapaz de compreender as possibilidades do texto para o pensamento. Este termo musical descreve o 'caminho' pelo qual Nietzsche é capaz de efetuar um desenvolvimento musical de seu texto contra 'ouvidos' indispostos." (p. 60).

35 Cf. STEGMAIER, W. Zur Frage der Verständlichkeit: Nietzsches Beitrag zum interkulturellen Kommunizieren und Philosophieren. In: Allgemeine Zeitschrift für Philosophie 32.2 (2007) p 107-119, aqui na p. 112. 
aludindo àquilo que está intimamente relacionado à música, vale dizer, a dança. Nietzsche se refere à dança como "ideal" do filósofo, na medida em que é necessário a ele ser um "bom dançarino". Música e dança expressam movimento, ou seja, a hipótese de que um texto não tem um significado para além do texto e nem sequer a possibilidade meta-interpretativa. Música e dança exprimem o caráter fluido da forma de escrita nietzscheana, a fluidez de significados e seu constante deslocamento de sentido; o movimento da dança, portanto, "escapa ao logocentrismo, à metafísica e à verdade pública de um escrito e uma leitura" tão caros "à tradição ocidental"36.

Em resumo, como se vê, Nietzsche sempre quis recolocar certos conceitos sob outros prismas. Por um lado, isso significa torná-los fluidos, na medida em que o horizonte de um mesmo conceito pode se deslocar tão logo suas condições de uso se modifiquem, podendo um único conceito receber, sob condições diferentes, novos significados. ${ }^{37}$ Por outro lado, trata-se de tomar distância de um conceito, por exemplo, com a noção de Vornehmheit, utilizando os mesmos mecanismos da tradição, mas com um sentido completamente diferente.$^{38}$ Por isso que Nietzsche, embora utilize os mesmos signos tradicionalmente utilizados, mesmo assim é mal-entendido. Ele desloca o horizonte dos conceitos, amplia suas Spielräume e confere a eles um novo sentido. Assim ele se distancia da tradição na própria tradição. A superação da compreensibilidade opera, pois, com um distanciamento da situação na situação. Trata-se de um jogo que ao mesmo tempo em que revela, oculta, de modo que é com o uso de paradoxos que Nietzsche também leva a termo o

36 BABICH, Babette E. On Nietzsche’s concinnity, p. 61.

37 Cf., p.ex., Nachlass/FP Primavera/Verão 1888, 16[33],KSA 13.492s./f.: "eu procurei na história pelas avaliações destes ideais invertidos de formação (descobrir e reinterpretar de uma maneira nova os conceitos 'pagão', 'clássico', 'nobre')."

38 TONGEREN, Paul v. Die Moral Nietzsches Moralkritik, p. 139: "Nietzsche relaciona a palavra Vornehmheit a uma tradição e começa seu capítulo com a 'história do surgimento'. Sua verdadeira questão, porém, objetiva não a uma transcrição do antigo ideal, mas a um esboço de um ideal para nosso tempo." 
projeto de superação da compreensibilidade, na medida em que amplia as margens de manobra para uma filosofia da interpretação e dos signos. Além disso, é fundamental levar em conta, para interpretar Nietzsche, a hipótese hermenêutica do texto 381 d'A Gaia Ciência, vale dizer, a hipótese de 'não ser compreendido' e todo seu cortejo de originalidade que carrega essa inversão hermenêutica. Assim ele inverte a compreensibilidade, distancia-se da Gemeinheit, opera em condições individuais de interpretação e se suspende da necessidade de pôr tudo em fórmulas ou conceitos. Esse seria o horizonte teórico para entender o significado da sua "arte do estilo".

\begin{abstract}
This paper aims to analyze what we call as the critical project of overcoming the understandability based on three hypotheses: a) the temporalization of thought, taking it back to the individual conditions of use of a concept, a sign, an action, etc.; b) this individuality of thought implies in understanding it in a fluid way, such that as soon as the individual conditions of use of a concept are altered, so is its meaning, c) Nietzsche no longer departs from the unconditional desire of being understood and, above all, universally and unequivocally understood, but rather from the hypothesis that "one does not only wish to be understood when writing, but in fact and in a certain way one may also wish not be understood".

Key-words: understandability - individualization - fluidity of meaning - incomprehensibility
\end{abstract}

\title{
referências bibliográficas
}

ALMEIDA, R. Nietzsche e o paradoxo. São Paulo: Loyola, 2005.

AZEREDO, V. Nietzsche e a interpretação: do mundo ao texto. In: BARRENECHEA, M.; FEITOSA, C.; PINHEIRO, P.; SUAREZ, R. (Orgs.). Nietzsche e as ciências. la. ed. Rio de Janeiro: 7 Letras, 2011, p. 202-213.

BABICH, B. On Nietzsche's concinnity: an analysis of style. In: Nietzsche-Studien 19 (1990) p. 59-80.

CONWAY, D. Nietzsche's On the Genealogy of Morals: a Reader's Guide. London, UK / New York, USA: Continuum, 2008. 
DIXSAUT, M. Nietzsche: Par-delà les antinomies. Chatou: Les Éditions de la Transparence, 2006.

KANT, I. "Von einem neuerdings erhobenen vornehmen Ton in der Philosophie". In: Werkausgabe in zwölf Bänden. Bd.6. Hrsg. von Wilhelm Weischedel. Frankfurt am Main: Suhrkamp, 1996.

KNEBEL, S. Historisches Wörterbuch der Philosophie. Bd. 9. Basel/Stuttgart: Schwabe \& Co. Verlag, 1972.

NIETZSCHE, F. Sämtliche Werke. Kritische Studienausgabe in 15 Bänden. (KSA) Hrsg. Giorgio Colli und Mazzino Montinari. Berlin/New York: DTV \& Walter de Gruyter, 1980.

SIMON, J. Der gewollte Schein: Zu Nietzsches Begriff der Interpretation. In: DJURIĆ, M u. SIMON, J. Kunst und Wissenschaft bei Nietzsche. p. 62-74.

STEGMAIER, W., Philosophie der Fluktuanz: Dilthey und Nietzsche. Göttingen: Vandenhoeck \& Ruprecht, 1992.

. Nietzsches Kritik der Vernunft seines Lebens: Zur Deutung von „Der Antichrist“ und „Ecce Homo“. In: Nietzsche-Studien 21 (1992), p. 163-183.

. Nietzsches "Genealogie der Moral". Darmstadt: Wissenschaftliche Buchgesellschaft, 1994.

. Philosophieren als Vermeiden einer Lehre: Inter-individuelle Orientierung bei Sokrates und Platon, Nietzsche und Derrida. In: Simon, Josef (Hrsg.), Distanz im Verstehen: Zeichen und Interpretation II. Frankfurt am Mai, 1995.

. Nietzsches Zeichen. In: Nietzsche-Studien 29 (2000), p. 41-69.

. Anti-Lehren: Szene und Lehre in Nietzsches Also Sprach Zarathustra. In: GERHARDT, V. (Hg.), Klassiker auslegen: Friedrich Nietzsche: Also Sprach Zarathustra, Berlin: Akademie Verlag, 2000.

. "Philosophischer Idealismus“ und die „Musik des Lebens: zu Nietzsches Umgang mit Paradoxien. In: Nietzsche-Studien 33 (2004), p. 90-128.

. Zur Frage der Verständlichkeit: Nietzsches Beitrag zum interkulturellen Kommunizieren und Philosophieren. In: Allgemeine Zeitschrift für Philosophie 32.2 (2007) p 107-119.

. Philosophie der Orientierung. Berlin/New York: Walter de Gruyter, 2008.

TONGEREN, Paul v. Die Moral von Nietzsches Moralkritk. Bonn: Bouvier Verlag, 1989.

WITTGENSTEIN, L. Philosophische Untersuchungen. Frankfurt am Main: Suhrkamp Verlag, 2003.

WOTLING, P. Nietzsche et le problème de la civilasation. Paris: PUF, 1995.

Artigo recebido em 11/09/2012.

Artigo aceito para publicação em 08/09/2012.

318 | cadernos Nietzsche 32, 2013 